\title{
Sustainable Development of Vietnam's Marine Tourism
}

\author{
Dr. Nguyen Xuan Dien \\ Academy of Finance, Vietnam
}

Ho Thi Hoa

Academy of Finance, Vietnam

Dr. Nguyen Thi Thu Huong

Academy of Finance, Vietnam

$$
\text { Le Thi Thuy }
$$

Academy of Finance, Vietnam

Nguyen Thi Quynh Nga

Academy of Finance, Vietnam

\begin{abstract}
Pham Thuy Nguyen
Vietnam Institute for Indian and Southwest Asian Studies

Vietnam Academy of Social Sciences (VASS), Vietnam
\end{abstract}

Received: July 20, 2019 Accepted: August 6, 2019 Published: September 16, 2019

doi:10.5296/emsd.v8i4.15461ＵRL: https://doi.org/10.5296/emsd.v8i4.15461

\begin{abstract}
Undoubtedly, marine tourism of Vietnam has successfully creating a new aspect for potential marine economy. However, the development of marine tourism in Vietnam still faces many difficulties, which pose some basic problems for marine tourism when aiming at sustainable development, in term of economy, society, and environment. This article will analyze the current situation of Vietnam's marine tourism towards sustainability based on three
\end{abstract}


economic-social-environment pillars. Moreover, the authors will propose some recommendations to develop Vietnam's marine tourism in a sustainable way in the future.

Keywords: Marine tourism, Sustainable development, Sustainable marine tourism

\section{Introduction}

Apparently, Vietnam has favorable conditions when owning a coastline of more than $3,260 \mathrm{~km}$ stretching along with the country in three directions East, South and Southwest; white sands; pristine bays; tropical islands all year round good, etc. In administrative terms, Vietnam has 28 provinces and cities which are direct-controlled municipality and located near the sea. It is a country with large coastal area in Southeast Asia with 125 beaches, most of which are beautiful. Furthermore, Da Nang beach has been voted as one of the six most charming beaches on the planet by Forbes magazine. Besides, Vietnam is also among 12 countries having the most beautiful bays in the world, such as Ha Long Bay, Nha Trang bay (Huu Thuy Giang Tran, 2016)

On the other hand, for many Vietnamese generations, the sea is not only a place to provide livelihoods, but also a space for the Vietnamese community to create a marine culture, with unique cultural heritage. It is a system of historical and cultural relics related to the marine environment, the seabed system, and the predecessors who had merit in conquering the sea, establishing and enforcing national sovereignty on the sea such as folk festivals of coastal residents; livelihood culture, residence culture; food culture, folk performances, indigenous knowledge, an so on. In fact, this is a rich resource to develop sustainable marine tourism. The sea has an important strategic position for Vietnam in terms of economy, society and environment.

Although there is great potential, Vietnam's marine tourism has not been really developed and has not yet become highly competitive. In order to develop marine tourism into a key economic sector, creating a driving force for sustainable socio-economic development, sustainable marine tourism development is essential. As a result, the authors choose to study the situation, explore the opportunities and challenges in developing marine tourism and propose some solutions for sustainable development of marine tourism in Vietnam.

\section{Literature Review}

Recently, many researches have pointed out the importance of sustainable tourism development based on three pillars, namely: economics, social and environmental. On that basis, the authors also identified some of the criteria used to assess sustainable tourism development. Marilena Papageorgiou (2016) emphasizes that the ever-growing coastal and marine space play an important role in tourism, which contribute significantly to economic growth. However, it is a controversy over whether marine tourism activities affect the environment or not. There is no doubt that marine spatial planning (MSP) is considered a promising procedure in addressing issues related to sea and coastal tourism. The author mentioned the important role of MSP in sustainable coastal and marine tourism when focusing on the following issues: (i) Good environmental conditions to develop tourism industry; (ii) Quality of coastal and coastal landscapes; (iii) Ability to adapt the impacts of 
climate change; (iv) Unoverwhelmed space regulations for coastal and marine space by tourism facilities and tourism activities; (v) The efficient allocation of human resources creating synergies between sectors and countries.

Lynne Eagle, Mark Hamann and David R.Low (2016) highlighted issues of environmental pollution and their consequences (especially plastic pollution and specific examples of the impact on sea turtles to illustrate the severity of the problem). The authors focus on reflecting human behavior that greatly affects environmental issues in marine tourism activities. The authors point out that there should be insights into the use of multidisciplinary research to identify barriers and create changes in people's behavior toward sustainable marine environments. Furthermore, Claudia Trave, Juerg Brunnschweiler, Marcus Sheaves, Amy Diedrich and Adam Barnett (2017) emphasize the important role of environmental protection in marine tourism in their research, especially for marine wildlife tourism (MWT). Some proposals have been made, such as: increasing researches on marine biology and ecosystems, examining the structure for policy implementation and increasing awareness of tourists ecosystems through active education; applying adaptive management frameworks and improving the handling rules for marine wildlife, and promoting different stakeholder participation and local communities in the development of MWT operations to ensure the health and long-term conservation of different species or habitats related to MWT's operations.

M.Angeles Ovieso- Garica, et.al (2019) mentioned the impact of the service environment on tourist satisfaction in the context of protected areas surrounding natural environment (PA). The authors used the questionnaire that provided for the sample of 520 tourists visiting the PA of Saltos de la Damajagua in Puerto (Dominican Republic). Additionally, the least-squares method, the facilities are determined to be satisfactory. The results show that while the information and food services are dissatisfied, improvements in service satisfaction will increase the satisfaction of tourists in PA. This result has implications for PA management, which provide tools to inform PA managers about how to accomplish their goals and protect PA's ecological integrity and satisfaction of tourists.

Drius Mita, Lucia Bongiorni et al. (2019) assessed Mediterranean coastal tourism and emphasized that tourism along the coast shares space and resource which led to many conflicts during usage like have negative impacts on resources and caused coastal habitat degradation. The authors discuss the complex relationships and tradeoffs between threats from coastal tourism and coastal ecosystems (which emphasize cultural relationship). The conceptual framework proposed and analyzed threats to highlight the negative impact of human-induced threats to Mediterranean coastal tourism. Thereby, the authors provide valuable insight to assist planners and plan in achieving synergy when managing coastal tourism activities in a sustainable way.

In Vietnam in recent years, some authors have studied the issue of developing marine tourism in a sustainable way, particularly as Pham Trung Luong (2004) who emphasized the important role in developing Vietnam marine tourism. However, in the development process, tourism activities are facing the environmental issue, such as marine ecosystem degradation, 
biodiversity, pollution, etc. These issues seriously affect the operation of marine tourism. Besides, Pham Trung Luong (2008) studied the development of sea and island tourism along the North Central Coast (Vietnam). He mentioned the role of tourism resources and human resources related to the development of marine tourism.

Nguyen Thu Hanh (2012) used field survey methods to assess the potential and current status of marine tourism development (including measuring, drawing, etc.) in coordination with the agencies to ensure that this article will be practical. This author has applied the sociological method of surveying tourists' opinion to determine accurate information about marine product demand and their assessment of the quality of marine resorts in North Central tourism. The collected information serves as a basis for proposing development solutions and meeting the needs of tourists. Considering the requirements related to the world and regional economic integration which are based on the potential advantages of marine tourism development, Huynh Thi My Le (2012) used statistical methods, synthesis, analysis, and comparison when analyzing the situation of Danang beach tourism development (a famous tourist city of Vietnam). Thereby, she suggested some useful suggestions for developing marine tourism in Danang. This author has set out the following criteria for evaluating marine tourism: (i) Developing tourism infrastructure; accommodation facilities, restaurants, shopping centers, and storage areas, amusement parks, entertainment; (ii) Developing marine tourism products and increasing the number of marine tourism types, improving the quality of marine tourism services; (iii) Developing human resources for marine tourism; (iv) Increasing contribution to marine tourism.

Chau Quoc Tuan, Nguyen Thi Minh Hien (2014) pointed out some unsustainability development risks of marine tourism, such as the environment pollution of the island and sea, the degradation of culture, etc. The authors provided a number of criteria to evaluate the sustainable development of marine tourism as following: (i) Assessment based on the economic aspect including evaluating marine tourism to new value to contribute to the economy. Simultaneously, it brings high and stable income to local workers compared to other economic sectors in the area; (ii) Social aspects including tourism impacts on creating jobs and increasing incomes for local workers to reduce poverty of communities and localities, affecting security, order and social safety in islands; (iii) The environmental concept is addressed to the following issues: assessing emissions from island and marine tourism activities and collection and treatment, coastal sea environment for sea and island tourism activities.

Phan Dong Nhut (2015) researched Quang Nam island tourism and pointed out elements of marine tourism products, such as: (i) Natural resources, including climate, landscape, mountains, sea, etc. (ii) Humanistic resources, cultural heritage, architectural works, habits and customs, etc. (iii) Facilities for tourism including restaurants, hotels and zones entertainment; (iv) Transportation system for tourism, such as: aircrafts, trains, cars; (v) Transports infrastructure for tourism activities, transport system, electricity and water system, etc. (vi) Economic and cultural environment, tourism service fees, social safety, urban intellectual standards and civilization. 


\section{Ml Macrothink}

Environmental Management and Sustainable Development

ISSN 2164-7682

2019, Vol. 8, No. 4

Though the potential of Vietnam's marine tourism is very large, the reality of exploiting marine tourism is not commensurate with this potential. Many previous researches mainly focus on analyzing the status of marine tourism development towards economic development. Some studies mentioned the orientation of sustainable development of marine tourism. Nevertheless, they have only been studied in a few small areas, the advanced research of the development of Vietnam's marine tourism under the criteria of sustainable development is still very little. Therefore, conducting research on the topic "Sustainable development of Vietnam marine tourism" is very necessary and objective and meets the demand of the tourism industry in the new period.

\section{Methodology}

In this research, the authors choose descriptive statistics methods. Data resources are based on analytical data from the General Department of Statistics, the General Department of Tourism of Vietnam over the years from 2005-2015. Marine tourism activities take place mainly in space of 138 cities (belong the provinces), the district/town has a beach (called the coastal strip), and 12 island districts in Vietnam.

\section{The Situation of Sustainable Development of Marine Tourism in Vietnam}

\subsection{Economy of Vietnam's Coastal Areas}

Marine tourism has achieved remarkable results in the past period, contributing to boosting economic growth. In the 2005-2015 period, GDP's growth rate of coastline areas reached approximately $13 \%$ annually, 1.6 times higher than the national growth rate of this period. In 2015, Vietnam's marine tourism reached \$4209.3, which was 2.4 times higher than that of 2005.

Table 1. Vietnam's marine tourism GDP

\begin{tabular}{|l|l|l|l|}
\hline Coastal area & $\mathbf{2 0 0 5}$ & $\mathbf{2 0 1 0}$ & $\mathbf{2 0 1 5}$ \\
\hline Nothern Coastal region & 507.44 & 634.3 & 1155.3 \\
\hline Ratio compared to the whole coastal area (\%) & 22.88 & 28.60 & 27.40 \\
\hline North Central Coastal region & 274.8 & 343.5 & 747.0 \\
\hline Ratio compared to the whole coastal area (\%) & 12.40 & 15.5 & 17.7 \\
\hline South Central Coastal region & 170.32 & 212.9 & 429.2 \\
\hline Ratio compared to the whole coastal area (\%) & 7.68 & 9.6 & 10.2 \\
\hline Coastal region & 822.96 & 1028.7 & 1877.8 \\
\hline Ratio compared to the whole coastal area (\%) & 37.12 & 46.4 & 44.6 \\
\hline Total marine tourism & $\mathbf{1 7 7 5 . 5 2}$ & $\mathbf{2 2 1 9 . 4 6}$ & $\mathbf{4 2 0 9 . 3}$ \\
\hline Rate compared to the whole country (\%) & $\mathbf{5 6 . 1 6}$ & $\mathbf{7 0 . 2}$ & $\mathbf{6 9 . 3}$ \\
\hline Whole country & $\mathbf{2 5 3 1 . 1 2}$ & $\mathbf{3 1 6 3 . 9}$ & $\mathbf{6 0 7 6 . 1}$ \\
\hline
\end{tabular}

Unit: Million USD

Source: Tourism Research and Development Institute

The structure of economic sectors in the coastal area has changed but not yet strong and unclear: the ratio of agricultural GDP to total GDP of coastal area decreased from $17.8 \%$ in 2010 to $16.6 \%$ in 2012 ; the ratio of GDP of industry and construction increased from $35.6 \%$ in 2010 to $35.8 \%$ in 2012; The corresponding figures for the service sector were $46.7 \%$ and 
$47.6 \%$, respectively. In marine and island economic sectors, the contribution of the economic sector which took place on the sea represented $98 \%$. In particular, oil and gas exploitation accounted for $46.2 \%$; seafood composed $22.4 \%$; maritime (including sea transport, seaport services) accounted for $18.9 \%$; marine tourism constituted $11 \%$; other sectors related to the exploitation of island potential, such as shipbuilding, seafood processing, and so on, made up 1.7\%. (Phan Ngoc Mai Phương et al, 2014)

In the 2005-2016 period, the state capital will support coastal provinces and cities throughout the country to invest in the construction of increasing tourist infrastructure, which upgraded from VND 550 billion in 2005 to VND 2237.7 billion in 2016. Interestingly, the most allocated provinces and cities are Ninh Binh, Hai Phong, Hue, Quang Nam, Quang Ninh, etc. Undoubtedly, it is foreign direct investment is an important source of investment, contributing significantly to marine tourism development in particular and tourism industry in general. Currently, many foreign investors from many countries and territories, such as Japan, The United States, The United Kingdom and Canada, etc are promoting direct investment in Vietnam, especially in the field of sea and island tourism. Foreign investment in tourism has been in 23 provinces and cities nationwide, accounting for $74.5 \%$ of investment projects in the field of tourism. In 2010, the whole country had 969 new licensed projects with a total registered capital of up to 17.23 billion USD, which was 2.5 times over same period in 2009 (Source: Tourism Research and Development Institue, 2015).

Considering the real tourism situation of FDI in coastal provinces and cities (where there is great potential for tourism in Vietnam), the total FDI capital has increased over the years. It has been mainly allocated in Binh Thuan and Da Nang in the period of 2007-2009. In the period of 2010-2017, many Vietnam's coastal provinces and cities have made more efforts in attracting FDI capital to develop tourism, such as Da Nang, Quang Nam, Binh Thuan, Thanh Hoa, Ba Ria- Vung Tau, etc. There are also many large projects registered for investment. For example: South Hoi An Resort projects (Quang Nam province) of Singapore investors with a total capital of up to 4 billion USD, Ho Tram Complex Resort (Ho Tram Strip), Dat Doc Con Dao beach tourist area (Six senses resort) and Song Ray Tourist Area (Ba Ria- Vung Tau). The Millenium international Group cooperates with Da Nang city People's Committee to develop a 5-star tourism project in Hoa Hai ward- Ngu Hanh Son district which has total area of 15 hectares and investment capital of up to 80 million USD (Department of Private Economic Research , 2018).

However, in fact, many Vietnam's localities have not had specific plans for developing sea and island tourism; policy mechanisms, promotion programs to attract investment are not reasonable. Actually, tourism promotion activities just only focus on promoting the public image, not creating resonance to intrigue investors. Moreover, FDI inflows in the field of sea and island tourism are quite large but the investment structure is not adequate. It often focuses on tourism real estate, especially towards a number of rich potential localities, such as Quang Ninh, Hoi An, Da Nang, Binh Thuan, and Nha Trang, etc, but less interested in developing sea and island tourism products.

Although marine tourism is limited in investment than other economic sectors, it still plays an 
important role in marine economic development. In order for marine tourism to further enhance the added-value advantages that contributed to the socio-economic growth of coastal areas and islands, more appropriate investment is needed with policies paying attention to the potential of development strengths of marine tourism in the next stages.

Vietnam coastal area annually attracts about $60 \%$ of domestic tourists of the whole country, especially tourists bathing and sea resort. In the period 2005-2015, the growth rate of domestic tourists to the coastal provinces of Vietnam tended to increase. The ratio of domestic tourists in coastal areas slightly increased slightly from $60.1 \%$ in 2005 to $60.4 \%$ in 2010 and $61 \%$ in 2015 . This shows that a large proportion of domestic tourists in the whole country came to these regions.

Table 2. Domestic tourists to coastal areas of Vietnam

\begin{tabular}{|l|l|l|l|}
\hline Coastal region & $\mathbf{2 0 0 5}$ & $\mathbf{2 0 1 0}$ & $\mathbf{2 0 1 5}$ \\
\hline Nothern Coastal region & 9681 & 12830.1 & 16000 \\
\hline Ratio compared to the whole coastal area (\%) & 32.5 & 3.1 & 3.4 \\
\hline North Central Coastal region & 2884.1 & 4301 & 5800 \\
\hline Ratio compared to the whole coastal area (\%) & 10.1 & 11.1 & 12.5 \\
\hline South Central Coastal region & 4297 & 5506.2 & 6300 \\
\hline Ratio compared to the whole coastal area (\%) & 14.2 & 14.2 & 13.5 \\
\hline Coastal region & 13413 & 16261.3 & 18450 \\
\hline Ratio compared to the whole coastal area (\%) & 43.1 & 41.6 & 39.6 \\
\hline Total marine tourism & 30234.6 & 38898.6 & 46550 \\
\hline Rate compared to the whole country (\%) & $\mathbf{6 0 . 1}$ & $\mathbf{6 0 . 4}$ & $\mathbf{6 1}$ \\
\hline Whole country & $\mathbf{5 0 4 3 3}$ & $\mathbf{6 4 4 0 1}$ & $\mathbf{7 6 3 0 0}$ \\
\hline
\end{tabular}

Unit: Thousand Passengers

Source: Tourism Research and Development Institute

International tourists come to Vietnam coastal provinces and cities accounting for an average of about $70-75 \%$ of the total international tourist visitors of the country. Although in the period 2005-2015, the proportion of international tourists in these regions decreased. Specifically, this rate was $77.2 \%$ in 2005 but only accounted for $71 \%$ in 2015 . Therefore, in the strategy of tourism development in Vietnam recently, the government focused on the sea and developing more diversified marine tourism products. Furthermore, in the coming years, the coastal area of Vietnam will be a promising destination for international tourists.

Table 3. International tourist visit to Vietnam coastal areas

\begin{tabular}{|l|l|l|l|}
\hline Coastal areas & $\mathbf{2 0 0 5}$ & $\mathbf{2 0 1 0}$ & $\mathbf{2 0 1 5}$ \\
\hline Northern Coastal region & 2384.1 & 3376.0 & 4150.0 \\
\hline Ratio compared to the whole coastal area (\%) & 37.7 & 33.6 & 27.5 \\
\hline North Central Coastal region & 377.4 & 2154.0 & 4540.0 \\
\hline Ratio compared to the whole coastal area (\%) & 16.6 & 21.4 & 28.2 \\
\hline South Central Coastal region & 406.7 & 767.0 & 1200.0 \\
\hline Ratio compared to the whole coastal area (\%) & 7.6 & 7.6 & 7.4 \\
\hline Coastal region & 2793.3 & 4263.0 & 5930.0 \\
\hline Ratio compared to the whole coastal area (\%) & 28.5 & 37.4 & 35.0 \\
\hline Total marine tourism & 5191.4 & 10056.0 & 22000.0 \\
\hline Rate compared to the whole country (\%) & $\mathbf{7 7 . 2}$ & $\mathbf{7 5 . 1}$ & $\mathbf{7 1 . 0}$ \\
\hline Whole country & $\mathbf{6 3 4 6 . 1}$ & $\mathbf{1 3 3 9 0 . 0}$ & $\mathbf{3 1 0 0 0 . 0}$ \\
\hline
\end{tabular}


Unit: Thousand passengers

Source: Tourism Research and Development Institute

In fact, the growth rate of Vietnam's coastal areas has increased continuously in recent years. Vietnam's marine tourism has contributed significantly to the overall national economic growth. Nonetheless, the process of economic growth still has some limitations. For instance, the government have not taken full advantage to develop marine tourism and attractions; and investment capital are spent unreasonably. In the next phase, there should be more specific orientations to develop marine tourism sustainably.

\subsection{Society of Coastal Areas in Vietnam}

Despite various difficulties, island tourism has played a critical role in creating jobs through the development of commercial services and activities, contributing to the improvement of local people life. Tourism development is also regarded as a significant way to attract people to live and do services in remote areas. Moreover, civil presence is the best way to affirm Vietnam's maritime and sovereignty.

\subsubsection{Income and Poverty Reduction}

Tourism is an economic sector which is capable of creating many jobs for society and contributes to income generations and poverty reduction towards a sustainable society.

It can not be denied that there is no adequate statistics of marine tourism in particular and tourism in general for efforts to eradicate hunger and reduce poverty in coastal areas and islands- where the poverty rate is considered quietly high. What is more? It can be seen that the tourism development in these regions has contributed significantly to promote economic development and changed the face of many localities in the region and improved people's lives. The poverty rate of some key provinces with marine tourism development tends to decrease significantly. Statistics of these provinces show a significant reduction in poverty rate, typically Quang Nam, Hue, Ninh Thuan, Binh Thuan, Khanh Hoa. These provinces had the strongest decline in the period 2005-2015. In 2006, three coastal provinces which had highest poverty rate was Quang Nam, Hue and Ninh Thuan. In detail, Quang Nam's rate was $22.8 \%$; Ninh Thuan's rate was $22.3 \%$; Hue's rate was $16.4 \%$. But by 2015 , this rate was $12.99 \%$ in Quang Nam; $15.48 \%$ in Ninh Thuan and $4.5 \%$ in Hue. Especially, poverty rate of Da Nang city has reached $0 \%$ in 2015 and now, Da Nang is considered the city that attracts the most tourists in Vietnam, this is one of the remarkable achievements. However, the poverty reduction still faces many obstacles, especially the rate of re-poverty still occurs in some regions and main mechanisms. Sadly, poverty reduction mechanisms are overlapping and difficult to implement.

Table 4. The poverty rate of some Vietnam's coastal provinces

\begin{tabular}{|l|l|l|l|}
\hline Local & $\mathbf{2 0 0 6}$ & $\mathbf{2 0 0 7}$ & $\mathbf{2 0 1 5}$ \\
\hline Quang Nam & 22.80 & 22.10 & 12.99 \\
\hline Da Nang & 4.00 & 3.80 & 0.00 \\
\hline Hue & 16.40 & 15.60 & 4.50 \\
\hline Ninh Thuan & 22.30 & 21.20 & 15.48 \\
\hline
\end{tabular}


Unit: \%

\begin{tabular}{|l|l|l|l|}
\hline Binh Thuan & 11.00 & 10.50 & 5.60 \\
\hline Khanh Hoa & 11.00 & 10.50 & 3.10 \\
\hline Ho Chi Minh city & 0.50 & 0.50 & 0.98 \\
\hline
\end{tabular}

Source: Statistical Yearbook of Vietnamese provinces

Currently, there have been some successful models of community tourism and ecotourism in some poor areas (typically the "homestay" tourism model). In fact, the life of people living in those places was very difficult. However, in recent years, the development of marine tourism creates a material premise to help people's lives improve significantly, people have the conditions to borrow money to buy fishing equipment and participate actively in the marine tourism development projects.

\subsubsection{Education}

Vietnam coastal strip is a large concentration of population with relatively high population density. In 2015, the total population of the 28 coastal provinces and cities direct-controlled municipality was 37.2 million, which represented $41.1 \%$ of the national population. The population growth rate in the $2000-2015$ period was $1.7 \%$ per year. The average population density in the coastal strip was 1.13 times higher than the national average population density. In addition, the coastal population was unevenly distributed between urban and rural areas, as well as other areas of the nation with the highest concentration in the central coastal region, which accounted for $36.8 \%$ of the coastal population of the country (Vietnam Statistical Yearbook, 2005, 2015).

Compared to the national average level, the education level of coastal residents is generally lower. The gap between the urban and rural education level is quite large. In urban areas, the proportion of people who have completed upper secondary or higher education is $47 \%$, while in rural areas this rate is only $30 \%$. Moreover, the educational level is higher, the difference is more clearly (Le Trong Binh, 2007).

\subsubsection{Electricity and Water}

In terms of the electricity systems and cleaned water in coastal areas and islands, the electricity for production and daily living activities is generally quite stable. Nevertheless, there is no specific data in islands. Furthermore, preliminary inquiries has shown that the number of households using electricity is very low there. Regarding water resources, lack of clean water is a common situation in rural coastal areas, especially in the communes and coastal districts of Northern and Central Vietnam. In recent years, with the support of the State, local authorities and other social organizations, etc., the situation of clean water supply in coastal localities has gradually improved. However, clean water still remains a challenge.

\subsubsection{Defense and Security}

In recent years, there are some troubles with national marine security. However, through negotiation and resolving the sovereignty of the maritime boundary between Vietnam and some other countries, the national defense and security forces have well implemented the task of protecting the sovereignty of Vietnamese sea. Since then, Vietnam's marine economy has 
many opportunities to grow stronger, including marine tourism sector.

\subsection{The Environment of Vietnam Coastal Areas}

The situation of marine and island pollution caused by overexploitation by localities in coastal sandy areas leads to lack of freshwater and beach erosion with increasing levels of seriousness. Catching seafood by mines and toxic chemicals quickly depletes marine resources, causing serious consequences for marine ecology. Tourism activities have a significant impact on the ecological environment and natural landscape of the sea.

\subsubsection{Firstly, Environmental Degradation}

Coastal environments and coastal waters are directly affected by marine tourism. In the marine tourism zones and destinations, environmental sanitation has not been regularly and thoroughly concerned by business organizations and individuals in this field. Garbage has not been collected and treated properly, leading to environmental pollution, especially in some beaches near residential areas, restaurants, hotels, etc. Additionally, wastewater treatment system has not been invested synchronously, hence in these areas, waste water is mainly discharged directly to the sea. Apparently, the awareness of environmental protection in general and the marine and coastal environment of tourists, in particular, is not high since there is always a situation of throwing away garbage, throwing leftover food and drinks indiscriminately on the beaches. Meanwhile, most of the domestic waste has not been treated, the main method is landfill. This has a significant impact on the landscape, natural environment, and water quality. As in the case of Cat Ba National Park with 5,400 hectares of water surface, from a pure island, the environment here has been degraded because there are thousands of tons of rubbish dumped directly into the sea every day (Source: Vietnam Institute of Oceanography warns, 2015)

Undoubtedly, the pollution of the marine environment has led to the degradation of marine biodiversity, typically coral ecosystems. According to the statistic from the Vietnam General Department of Sea and Islands, there are about $20 \%$ of poor coral cover ( $0-25 \%$ coverage), $60 \%$ of low level (26-50\%), 17\% good (51-75\%) and only 3\% very good (over $75 \%$ ). (Vietnam Institute of Oceanography warns, in 2015), he content of monitored COD and NH4 parameters in the period of 2011-2015 in most of the northern and southern sea areas of Vietnam has been over the threshold of standards (aquaculture and bathing purposes).

\subsubsection{Secondly, Coastal Erosion}

Coastal erosion directly affects the existence of coastal resorts. According to the Huu Thuy Giang Tran (2016), Vietnam's coastline is 3,260 km long (ranked 32 out of 156 countries and territories with the sea). In recent years, Vietnamese scientists have collected a considerable amount of documents about the current state of coastal erosion and the first step is to understand the causes, on that basis, to propose preventive measures to protect the coast. The study result obtained by the author Vu Van Phai (2009) conducted a construction survey based on the field suralong the coast of Vietnam from 1991 to 2009 and showed that the phenomenon of sea erosion appeared in many places including the edge of the Northern Delta, South and Central Coast of Vietnam. 


\subsubsection{Thirdly, Forests in Coastal Areas and Islands Declined}

Moreover, according to the results of the national forest inventory (Prime Minister's Decision No 03/2001/QD/TTg dated January 5, 2001), the area of mangrove forests (mangroves) in Vietnam is calculated by $21 / 12 / 1999$ was 156,608 ha. In which natural mangrove area is 59,732ha, making up $38.1 \%$ and the area of mangrove forest is 96,876 ha accounting for $61.95 \%$.

In the face of serious environmental degradation, currently, in order to serve tourism development, many green projects to protect the natural environment and islands have been implemented. Hence, it was helpful and efficient to reduce exploitation activities which destroy the environment and ecosystem.

\section{Results and Discussion}

\subsection{Advantages}

Firstly, marine tourism has achieved a high growth rate and contributed significantly to the renovation of the country, creating a driving force for economic development and a foundation to protect the of Vietnam marinetime sovereignty. Furthermore, the structure of coastal economic sectors has changed in the modern direction.

Secondly, the development of marine tourism has created jobs, contributed to poverty reduction in coastal provinces, and increased income opportunities for people to improve their education and awareness to protect natural landscape and tourism environment.

Thirdly, issues of marine environmental protection in tourism activities have begun to be focused on through management activities of state management agencies, as well as the behavior of local people and tourists are beginning to improve.

\subsection{Defects}

Initially, Vietnam is a poor and developing nation with many beaches. There are about one-third of Vietnam's population living in coastal areas and directly affected by the sea. In the past period, although the open-door policy has been implemented, it is still slower than in other countries in the region. In the next period, more open and integration policies are required.

Investment capital for marine tourism in Vietnam is limited, especially investment from the budget to upgrade tourism infrastructure, facilitating access to potentials and places to visit marine tourism.

Tourism development policies including marine tourism are not synchronized, nor promoting development investment, especially in the segment of the high quality marine tourism market.

Marine tourism development is facing the risk of natural resource depletion and environmental pollution, due to shortcomings in industry planning and territorial planning, which leads to overlap in exploitation and use of tourism resources; and ineffective management in socio-economic development. 


\section{Macrothink}

Environmental Management and Sustainable Development

ISSN 2164-7682

2019, Vol. 8, No. 4

Lastly, sea-level rise caused by climate change in Vietnam, as the phenomenon is posing grave challenges to the ecosystem, biodiversity, natural resources as well as marine tourism development.

\section{Conclusion and/or Policy Implications}

Developing sea and island tourism is the way to exploit the comprehensive value of the sea. Marine tourism not only profits to the tourism industry itself but also creates a great spread in residential areas and other economic sectors. It also contributes majorly to protect the marine environment and ensure national security and defense. Moreover, the sustainable tourism development to achieve the socio-economic environmental objectives is an important task and is the aim in the development of marine tourism in particular and Vietnam's tourism industry in general. Some recommendations are proposed as following:

\subsection{Proposals to the Ministry of Culture, Sport, and Tourism of Vietnam}

It is necessary to promulgate guidelines for localities with marine tourism potentials to develop tourism development strategies based on concretizing national development strategies.

Guiding and supporting local enterprises to manage information, market, and attain quality management skills and technology innovation are also vital.

The Ministry should organize scientific research related to sustainable development of marine tourism, and direct exploitation of marine tourism resources at the macro level.

\subsection{Recommendations to the Coastal Localities}

Firstly, it is necessary to have a plan to concentrate on the human resource by using and training human resources effectively for marine tourism, improving the quality of tourism staff, and linking localities in training human resources for tourism.

Secondly, it is suggested that the localities should enhance the direction of the People's Committee leaders, departments and agencies, promote administrative reform, and promulgate many investment incentive and preferential policies.

Thirdly, strengthening activities of tourism business units, creating cohesion with state management agencies on tourism with enterprise, creating favorable conditions for business to connect, and exchanging experiences with each other.

Fourthly, enhancing awareness of businesses, local communities, and tourists about the issue of marine and coastal environment protection.

\section{References}

Chau Quoc Tuan, \& Nguyen Thi Minh Hien. (2012). Evaluate the development of sustainable sea and island tourism in Bai Tu Long Bay. Journal of Science and Development, 6.

Claudia Trave, Juerg Brunnschweiler, Marcus Sheaves, Amy Diedrich, \& Adam Barnett. (2017). Are we killing them with kindness? Evaluation of sustainable marine wildlife tourism. 
Biological Conservation, 209, 211-222. https://doi.org/10.1016/j.biocon.2017.02.020

Department of Private Economic Research (coordination of Vnexpress region and TAB Tourism Advisory Council). (2018). Investment and solutions to develop quality Vietnamese tourism, Vietnam High-level Tourism Forum, Vietnam Economic Forum

Drius, M., Bongiorni, L., Depellegrin, D., Menegon, S., Pugnetti, A., \& Stifter, S. (2019). Tackling challenges for Mediterranean sustainable coastal tourism: An ecosystem service perspective. Science of The Total Environment, 652, 1302-1317.

https://doi.org/10.1016/j.scitotenv.2018.10.121

General Statistics Office of Vietnam. (2005). Vietnam Statistical Yearbook 2005

General Statistics Office of Vietnam. (2015). Vietnam Statistical Yearbook 2015

Huu Thuy Giang Tran. (2016). An exploration of the potential for sustainable tourism development on selected Vietnamese islands, Southern Cross University ePublications@SCU

Huynh Thi My Le. (2012). Da Nang beach tourism development. University of Danang

Institute of tourism development strategy. (2015). Project of developing sea, island and coastal tourism by 2020. Vietnam National Administration of Tourism

Le Trong Binh. (2012). Some breakthrough solutions to developing coastal and coastal tourism in Vietnam. Tourism Research and Development Institute, Vietnam National Administration of Tourism.

Lynne Eagle, Mark Hamann, \& David R. Low. (2016). The role of social marketing, marine turtles and sustainable tourism in reducing plastic pollution. Marine Pollution Bulletin, 107(1), 324-332. https://doi.org/10.1016/j.marpolbul.2016.03.040

M. Angeles Ovieso-Garcia, Manuela Vega-Vazquez, Mario Castellanos-Verdugo, \& Francisco Orgaz-Aguera. (2019). Tourism in protected areas and the impact of service area on tourist satisfaction, key in sustainability. Journal of Destination Marketing \& Management, 12, 74-83. https://doi.org/10.1016/j.jdmm.2019.02.005

Marilena Papageorgiou. (2016). Coastal and marine tourism: A challenging factor in Marine Spatial Planning. Ocean \& Coastal Management, 129, 44-48.

https://doi.org/10.1016/j.ocecoaman.2016.05.006

Ministry of Planning and Investment. (2013). Circular guiding the implementation of some contents of Vietnam Sustainable Development Strategy for the period 2011-2020, No. 02/2013/TT-BKHDT

Nguyen Tac An. (2015). Red alert pollution of the marine environment. Vietnam Institute of Oceanography.

Nguyen Thanh Binh. (2010). Sustainable development of Vietnam's marine tourism oriented to 2030 and implementation solutions. Trade Journal, 21.

Nguyen Thi Hong Lam. (2013). Tourism economy in the North Central provinces in 


\section{Macrothink}

Environmental Management and Sustainable Development

ISSN 2164-7682

2019, Vol. 8, No. 4

international economic intergration. Ho Chi Minh National Academy of Political and Public Administration.

Nguyen Thu Hanh. (2012). The current status and solutions to develop national sea resorts in North Central tourism.

Pham Trung Luong. (2004). Developing sustainable marine tourism from an environmental perspective. Journal of Tourism and Environment.

Phan Dong Nhut. (2015). Research on Quang Nam island and marine tourism products, University of Social Sciences and Humanities.

Phan Ngoc Mai Phuong et al. (2014), Coastal economic development in the spirit of Vietnam sea strategy. Journal of External Information, 124(07).

Prime Minister. (2012). Decision No. 432/QD-TTg Approving Vietnam sustainable Development Strategy for period of 2011-2020.

Prime Minister's Decision No 03/2001/QD/TTg dated January 5, 2001

Research Institute for Tourism Development. (2012). in the topic "Scientific basis and solutions for sustainable tourism development in Vietnam"

Vietnam Environment Law. 2014

Vu Van Phai. (2006). Vietnam coastal erosion and Global climate change. National University

\section{Copyright Disclaimer}

Copyright for this article is retained by the author(s), with first publication rights granted to the journal.

This is an open-access article distributed under the terms and conditions of the Creative Commons Attribution license (http://creativecommons.org/licenses/by/3.0/). 